\title{
KAJIAN PERBANDINGAN PERTUMBUHAN IKAN BARONANG (SIGANUS CANALICULATUS) DALAM KERAMBA JARING DASAR PADA KONDISI PADANG LAMUN YANG BERBEDA DI PULAU LANTANG PEO KABUPATEN TAKALAR
}

\author{
(Comparative Study of Growth Baronang Fish (Siganus Canaliculatus) in, Basic Net \\ Cages in Conditions Different Seagrass BedsIn Lantang Peo Island, Takalar District)
}

\section{Muh. Aryan R. Suci 1), Andi Tamsil 2) dan Harlina ${ }^{3)}$}

1) Mahasiswa Pasca-Sarjana Universitas Muslim Indonesia

2) Dosen Program study Manajemen Pesisir dan Teknologi Kelautan Pasca Sarjana UMI Makassar

3) Dosen Program Study Ilmu Perikanan Pasca Sarjana UMI Makassar

Korespondensi: muharyanrsuci@gmail.com

Diterima: tanggal 10 Juli 2020; Disetujui 25 Agustus 2020

\begin{abstract}
Muh. Aryan R Suci. Growth of Baronang Fish (Siganus canaliculatus) in Basic Net Cages in Different Seagrass Conditions on Lantang Peo Island, Takalar Regency. Lantang Peo Island which is one of the islands which is covered by several types of seagrass. Data collection was carried out from September to October 2016 at the Lantang Peo estuary. The first treatment is observation of density, cover and identification of seagrass. The second treatment is measuring water quality and the last one is measuring the weight and length of the baronang fish. Observation of seagrass species obtained Enhalus accoroides and Thalassia hempichii species. The total density of seagrass at Station I was 47 (teg / m2) 10.03\% cover of seagrass, $70(\mathrm{teg} / \mathrm{m} 2)$ density of seagrass at Station II was $17.12 \%$ and the total density of seagrass at Station III was 90 (teg / m2) 18.13\%. Observation of the absolute growth of baronang fish weight at station I of $1 \mathrm{gr}$. At station II the absolute weight growth of fish is $3 \mathrm{gr}$ and at station III the absolute weight growth of fish is $5 \mathrm{gr}$. Observations of the absolute length increase of fish at Station I were $1 \mathrm{~cm}$, the absolute length increase of fish at Station II was $2 \mathrm{~cm}$ and the absolute length increase of fish at Station III was $3 \mathrm{~cm}$. This difference occurs due to the different density structure of the seagrass at each station.
\end{abstract}

Keywords: bottom net cages, seagrass beds, baronang fish, lantang peo islands

\section{ABSTRAK}

Muh.Aryan R Suci. Pertumbuhan Ikan Baronang (Siganus canaliculatus) dalam Keramba Jaring Dasar pada Kondisi Lamun yang Berbeda di Pulau Lantang Peo, Kabupaten Takalar. Pulau Lantang Peo yang merupakan salah satu pulau yang ditumbuhi oleh beberapa jenis lamun. Pengumpulan data dilakukan sejak September hingga Oktober 2016 di muara Lantang Peo. Perlakuan pertama adalah pengamatan kepadatan, tutupan dan identifikasi lamun. Perlakuan kedua adalah pengukuran kualitas air dan yang terakhir adalah pengukuran berat dan panjang ikan baronang. Pengamatan jenis lamun didapatkan jenis Enhalus accoroides dan Thalassia hempichii. Total kepadatan lamun di stasiun I adalah 47 (teg/m2) penutupan lamun 10.03\%, kepadatan lamun stasiun II 70 (teg/m2) penutupan lamun $17.12 \%$ dan total kepadatan lamun stasiun III penutupan 90 (teg/m2) lamun 18,13\%. Pengamatan pertumbuhan mutlak bobot ikan baronang di stasiun I 
sebesar 1 gr. Pada stasiun II pertumbuhan bobot mutlak ikan 3 gr dan pada stasiun III pertumbuhan bobot mutlak ikan 5 gr. Pengamatan pertambahan panjang mutlak ikan di Stasiun I sebesar $1 \mathrm{~cm}$, pertambahan panjang mutlak ikan di Stasiun II sebesar $2 \mathrm{~cm}$ dan pertambahan panjang mutlak ikan di Stasiun III sebesar $3 \mathrm{~cm}$. Perbedaan ini terjadi akibat struktur kepadatan lamun yang berbeda di setiap stasiun.

Kata kunci: Keramba jaring dasar, padang lamun, ikan baronang, pulau lantang peo.

\section{PENDAHULUAN}

Padang lamun memiliki produktivitas primer dan sekunder yang sangat tinggi dan mendukung kelimpahan dan keragaman ikan (Gilanders, 2006).Namun, ada beberapa komunitas yang menjadikan lamun sebagai makanannya.Misalnya, ikan baronang jenis Siganus canaliculatus (Lamerburu, 2009).

Ikan baronang (Siganus canaliculatus) banyak dijumpai hidup di daerah padang lamun. Hal ini terkait dengan kebiasaan makanan ikan baronang yang cenderung herbivora, memakan tumbuhan lamun dan epifit yang berasosiasi dengan lamun (Rappe, et al,. 2011).

Habitat ikan baronang yang luas ini disebabkan dalam mencari makan dan berkembang biak, baronang berpindah dari satu habitat ke habitat lain, yang kondisi lingkungannya berbeda. Ikan baronang digolongkan herbivora (pemakan tumbuhan) atau vegetaris.Ikan baronang ini banyak ditemui disekitar padang lamun dan daerah terumbu karang (Zulfikar, et al,. 2013).

Di Pulau Lantang Peo Kabupaten Takalar ada vegetasi padang lamun yang hidup. Namun ancaman yang masuk ke daerah tersebut juga besar. Mengingat besarnya peranan ekosistem padang lamun terhadap kehidupan ikan baronang (Siganus canaliculatus) dan banyaknya ancaman-ancaman dari berbagai aktifitas manusia serta pemahaman mengenai potensi padang lamun untuk budidaya ikan baronang (Siganus canaliculatus) yang masih sangat kurang mengakibatkan rusaknya dan menurunnya peranan ekologis dari ekosistem tersebut, maka usaha konservasi padang lamun menjadi mutlak untuk dilakukan.

\section{METODE PENELITIAN}

\section{Waktu dan Tempat Penelitian}

Penelitian ini akan dilaksanakan pada bulan September hingga oktober 
2016 di wilayah pesisir Pulau Lantang Peo, Kabupaten Takalar.

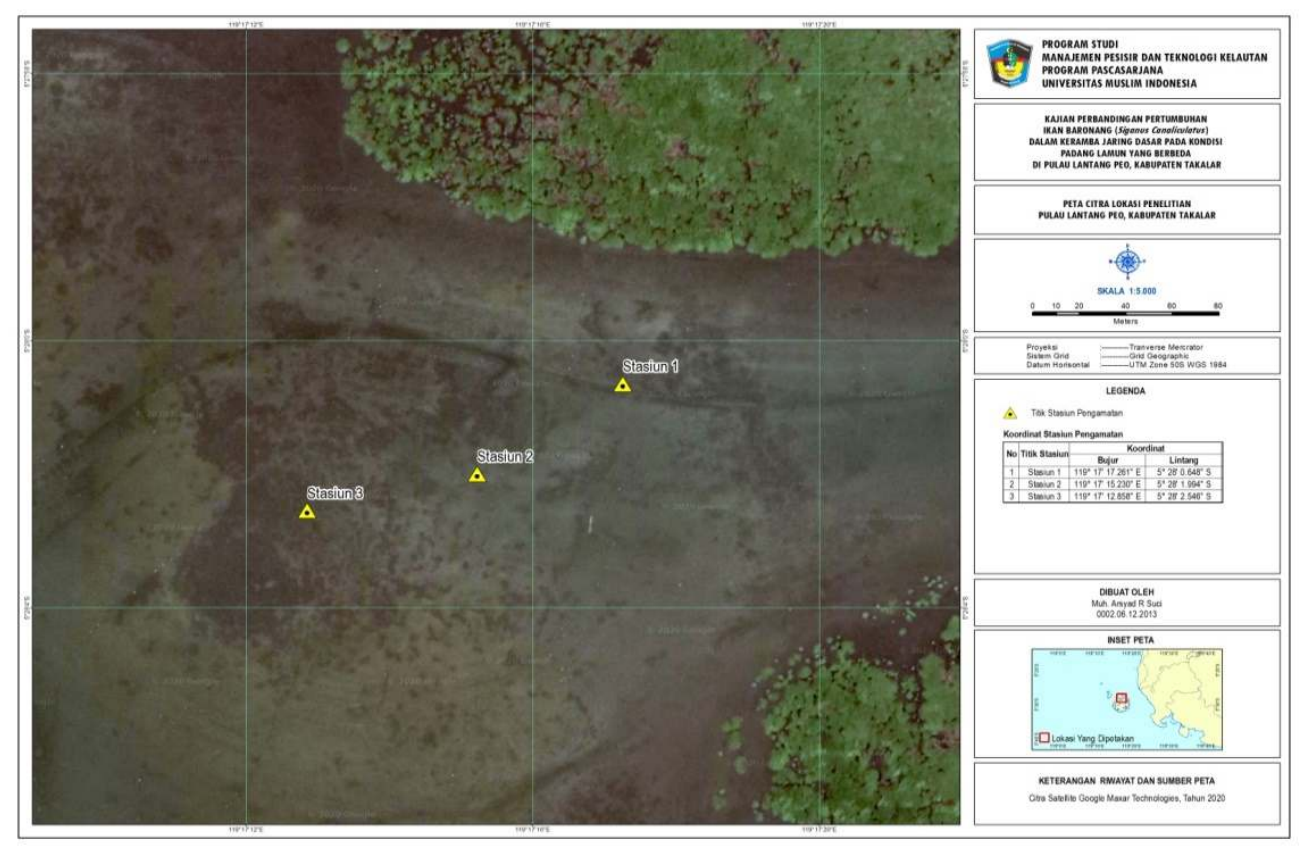

Gambar 1. Peta lokasi penelitian

\section{Alat dan Bahan}

Alat yang digunakan pada penelitian ini adalah thermometer, ph meter, refraktometer, do meter, tongkat skala, layangan arus, kerambajaring dasar, alattulis, dan kaca mata renang. Bahan yang digunakan adalah ikan baronang (Siganus canaliculatus).

\section{Jenis dan Sumber Data}

Data dari penelitian ini terdiri dari data primer dan data sekunder. Data Primer yaitu data yang diperoleh secara langsung di lapangan dengan melakukan kajian penentuan lokasi, pengukuran kualitas air dan pertumbuhan baronang. Data Sekunder yaitu data penunjang yang dikumpulkan dari beberapa literature penelitian dan instansi terkait yang berhubungan dengan materi penelitian maupun laporan tertulis yang dipandang relevan dengan penelitian

\section{Teknik Pengumpulan Data}

Survey, teknik survey ini digunakan untuk mengumpulkan data-data yang berkaitan dengan penelitian. Teknik ini dipakai dalam penelitian lapangan yang bermanfaat untuk mengetahui kondisi awal lokasi penelitian. Dokumentasi, teknik ini digunakan mengumpulkan data-data yang berkaitan dengan penelitian. Ada beberapa data dokumentasi yang dikumpulkan seperti wawancara, lampiran foto penelitian dan literature pendukung penelitian. 


\section{Prosedur penelitian}

Terlebih dahulu dilakukan survey lokasi penelitian untuk mengetahui keadaan umum lokasi, untuk menentukan titik-titik lokasi karamba.Tentunya, menentukan lokasi harus memperhatikan pasang surut air laut. Adapun titik lokasi penelitian itu yang telah disurvey adalah stasiun padang lamun dengan tingkat kerapatan jarang, stasiun padang lamun dengan tingkat kerapatan sedang dan stasiun padang lamun dengan tingkat kerapatan tinggi.

Pengamatan lamun dilakukan pada saat ait surut. Metode yang digunakan pada pengmatan lamun ini menggunakan metode transek kuadran dengan luas transek $1 \mathrm{X} 1 \mathrm{~m}$, dengan panjang line transek $50 \mathrm{~m}$. pada setiap stasiun dilakukan 3 kali pengulangan. Sebelum mendistribusi alat dan bahan ke titik lokasi penelitian maka dilakukan pengukuran parameter kualitas air yaitu suhu, kecepatan arus, salinitas air laut, kedalaman, oksigen terlarut (DO) dan $\mathrm{pH}$.

Penentuan stasiun pengamatan berdasarkan criteria hasil pengukuran kerapatan lamun yang telah diukur sebelumnya. Stasiun pengamatan dibagi menjadi 3 stasiun. Stasiun pertama pada lokasi padang lamun dengan tingkat kerapatan jarang. Stasiun kedua pada lokasi lamun kerapatan sedang dan stasiun ketiga pada lokasi lamun kerapatan tinggi. Melakukan pemasangan keramba jaring dasar dengan membuat kerangka keramba dari pipa paralon yang beisi cor. Ukuran plot tiap stasiun yaitu $1 \times 1$ meter sebanyak 3 plot. Jaring diikat pada kerangka. Kemudian dipatok dengan kayu agar tidak terbawa arus.

Bibit ikan baronang diambil dari alam.Ukuran panjang awal ikan yaitu 10 cm dengan berat awal 18 gram. Sebelum penebaran, terlebih dahulu harus diketahui panjang dan berat awal ikan untuk mendapatkan hasil yang optimal. Ikan yang ditebar dalam keramba adalah 10 ekor/plot.

\section{Analisis Data}

Menghitung kerapatan dan penutupan lamun.Kerapatan Jenis Lamun yaitu jumlah individu lamun (tegakan) per satuan luas. Kerapatan jenis lamun dihitung dengan rumus berikut : (Brower et al,. 1990).

$$
\mathrm{Di}=\mathrm{Ni} / \mathrm{A}
$$

Keterangan :

Di : Jumlah Individu (tegakan) ke-i per satuan luas

$\mathrm{Ni}$ : Jumlah individu (tegakan) ke-i dalam transek kuadrat

A : Luas transek kuadrat

Penutupan lamun merupakan luasan area yang ditutupi oleh lamun.Persen penutupan lamun dapat 
dihitung dengan menggunakan metode Saito dan Atobe sebagai berikut (English et al,. 1994):

$$
\mathrm{C}=\underset{\Sigma \mathrm{f}}{\Sigma(\text { mi.fi }}
$$

Keterangan :

C : Persen penutupan lamun (\%)

mi : Persen nilai tengah kelas ke-i

fi : Frekuensi kemunculan jenis (jumlah sub-transek yang memiliki kelas yang

sama untuk spesies ke-i)

f : Jumlah keseluruhan sub-transek

Menghitung panjang dan bobot ikan.Pertumbuhan mutlak adalah laju pertumbuhan total ikan. Rumus untuk mencari pertumbuhan mutlak adalah (Basyari et al,. 1987).

$$
\mathrm{GR}=(\mathrm{Wt}-\mathrm{Wo})
$$

Keterangan :

GR : Growth Rate / pertumbuhan mutlak (gr)

Wt : bobot rata - rata akhir (gr)

$\mathrm{W}_{0}$ : bobot rata - rata awal (gr).

\section{HASIL DAN PEMBAHASAN}

\section{Gambaran Umum Lokasi \\ Penelitian}

Salah satu Pulau yang dijadikan tempat pengambilan ikan beronang adalah Pulau Tanakeke yang berada di dekat Galesong kabupaten Takalar. Pulau Tanakeke dijadikan tempat pengambilan ikan beronang karena menurut para nelayan yang sering menangkap ikan, Mengingat ikan beronang senang dikonsumsi oleh masyarakat(Faika, 2010).

Secara geografis Pulau Tanakeke terletak di sebelah selatan Selat Makassar, tepatnya pada koordinator antara $11^{\circ} 14^{\prime} 22^{\prime \prime}$ - $119^{\circ} 20^{\prime} 29^{\prime \prime}$ ' BT dan 5'26'43" -5॰32'34" LS (Peta Rupa Bumi Indonesia, lembar 2010-24 dan 2010-52, 1999) dan secara oceanografis dipengaruhi oleh Laut Flores, Selat Tanakeke dan Selat Makassar.Secara administratif, Pulau Tanakeke terdiri dari 2 desa yaitu desa Maccini Baji meliputi Kampung Tompotana, Cambayya, Kampung Bugisi', Dande Dandere, Balang datu Luar, Balangdatu dalam, Cambangloe (Balangloe dan Cambang cambangang), Batu Ampara dan Desa Mattiro Baji meliputi Kampung Rewatayya, Kalukuang, Lantang Peo, Satangnga, Bauluang, dan Dayang Dayangang.

Untuk menuju lokasi penelitian Kampung Rewatayya dan Kalukuang merupakan kampung yang terdekat ke ibukota kecamatan, berjarak 10 mil laut, yang dapat ditempuh dengan menggunakan perahu $( \pm 2-3 \quad$ GT $)$, bermesin $12-22 \mathrm{pK}$ dengan waktu tempuh \pm 1 jam dari daratan Takalar Lama (Mutmainnah, 2005). 
Berdasarkan hasil wawancara, dapat disimpulkan bahwa dominan dari masyarakat Pulau Tanakeke adalah nelayan dan pekerja tambak, ada juga yang berperan sebagai petani rumput laut. Kebijakan dari pemerintah untuk transmigrasi memberikan lahan untuk masyarakat transmigran di Pulau tersebut untuk memanfaatkan lahan yang disediakan untuk digunakan sebagai kebun campuran dan berladang.

PulauLantang Peo, yang merupakan salah satu gugusan pulau di desa mattiro baji memiliki teluk, yang ditumbuhi oleh beberapa jenis lamun. Pulau ini juga dikelilingi oleh mangrove. Di teluk Lantang Peo inilah dilakukan penelitian dengan membagi menjadi 3 stasiun yang berdasarkan hasil survey lokasi beberapa bulan yang lalu dengan melihat kerapatan lamun. Assosiasi dua spesies antara Thalassia hemprichii dengan Enhalus acoroides didapatkan di daerah Teluk yang kondisi perairannya relatif tenang dan substrat dasarnya terdiri dari pasir berlumpur yang memungkinkan tumbuh suburnya lamun pada daerah tersebut. Kondisi lingkungan daerah teluk yang tenang, menyebabkan terjadi akumulasi lumpur yang tinggi pada substrat. Pada kondisi lingkungan yang demikian hanya spesies tertentu yang bisa bertahan terutama spesies Thalassia hemprichii dan Enhalus acoroides, dengan keanekaragaman jenis lamun tergolong rendah (Arifin, 2005).

\section{Kondisi Parameter Lingkungan}

Secara umum, kondisi parameter lingkungan di pesisir Pulau Lantang peo, Kabupaten Takalar masih dalam kategori yang cukup baik untuk kelangsungan hidup ikan baronang (Siganus canaliculatus). Angka parameter lingkungan dapat dilihat dalam tabel 1 berikut ini;

Tabel 1. Nilai parameter lingkungan selama penelitian pada setiap stasiun pengamatan.

\begin{tabular}{|c|c|c|c|c|c|c|}
\hline \multirow{2}{*}{$\begin{array}{l}\text { Parameter } \\
\text { lingkungan }\end{array}$} & \multicolumn{6}{|c|}{ Stasiun Pengamatan } \\
\hline & Stasiun I & $\begin{array}{l}\text { Rata- } \\
\text { rata }\end{array}$ & Stasiun II & $\begin{array}{l}\text { Rata- } \\
\text { rata }\end{array}$ & Stasiun III & $\begin{array}{l}\text { Rata- } \\
\text { rata }\end{array}$ \\
\hline Salinitas $\%$ & $34-35$ & 34.5 & $34-35$ & 34.5 & $34-35$ & 34.5 \\
\hline DO (mg/l) & $4.20-5.16$ & 4.68 & $5.24-6.56$ & 5.90 & $6.60-6.88$ & 6.74 \\
\hline arus (m/det) & $0.10-0.12$ & 0.11 & $0.10-0.13$ & 0.11 & $0.09-0.12$ & 0.10 \\
\hline Suhu $\left({ }^{\circ} \mathrm{C}\right)$ & $33-34{ }^{0} \mathrm{C}$ & $33,5{ }^{\circ} \mathrm{C}$ & $33-34{ }^{0} \mathrm{C}$ & $33,5^{\circ} \mathrm{C}$ & $33-34{ }^{0} \mathrm{C}$ & $33,5^{\circ} \mathrm{C}$ \\
\hline $\mathrm{pH}$ & $7.520-7,580$ & 7.55 & $7.760-7.810$ & 7.78 & $7.830-7,870$ & 7.85 \\
\hline Kedalaman & $40-128$ & 84 & $58-136$ & 97 & $56-138$ & 97 \\
\hline
\end{tabular}




\section{Salinitas}

Pada umumnya, nilai salinitas yang didapatkan pada tiap stasiun adalah sama karena lokasi ketiga stasiun berdekatan, yang membedakan hanya pada kerapatan lamunnya. Hasil pengukuran salinitas dari ketiga stasiun menunjukan angka yang cocok untuk kelangsungan hidup ikan baronang (Siganus canaliculatus). Kisaran salinitas perairan yang didapatkan selama penelitiannya berkisar antara $29.40 \%$ - 33,30 \%o yang masih optimal bagi petumbuhan kehidupan ikan.

\section{DO}

DO yang terukur sebesar 4 - 7 ppm. Hal ini disebabkan karena oksigen terlarut digunakan untuk proses metabolisme dalam tubuh dan berkembang biak. Untuk pertumbuhan ikan-ikan laut, kandungan oksigen terlarut dalam air minimal 4 ppm, sedangkan kandungan optimum adalah antara 5-6 ppm (BPP-PSPL, 2009).

\section{Kecepatan Arus}

Hasil dari arus yang tidak kuat ini menyebabkan permukaan daun lamun yang tumbuh disana penuh ditumbuhi oleh epifit berikut material lain yang tertampung diantara algae tersebut sehingga ikan baronang senang berada disekitar padang lamun untuk bias bertahan hidup. Kecepatan arus di lokasi penelitian ini tidak begitu kuat karena dikelilingi oleh mangrove yang menahan angin dari laut bebas.

\section{Suhu}

Semua nilai suhu pada tiap stasiun dapat dikatakan sama karena lokasi di tiap stasiun ini berdekatan kemudian waktu pengukuran tiap stasiun juga dilakukan pada waktu yang sama. Menurut Lam (1974) kisaran suhu optimal bagi kehidupan Siganus canaliculatus adalah antara $25^{\circ} \mathrm{C}-34^{\circ} \mathrm{C}$.

\section{5. $\mathrm{pH}$}

Semua kondisi pH pada lokasi penelitian masih dalam kondisi optimal untuk kelangsungan hidup ikan baronang (Siganus canaliculatus.) Usaha budidaya ikan agar berhasil dengan baik pH air sebaiknya berkisar antara 6,5 9,0 dan pertumbuhan optimal ikan terjadi pada pH 7- 8 (BPP-PSPL, 2009).

\section{Kedalaman}

Kedalaman air pada lokasi penelitian masih cukup baik untuk kelangsungan hidup ikan baronang (Siganus canaliculatus).

\section{Presentase Karakteristik Lamun}

Berdasarkan hasil penelitian di perairan Pulau Lantang Peo, didapatkan 2 jenis lamun yang berasal dari family Hidrocaritaceae, yang terdiri dari spesies Thalassia hemprichii dan Enhalus acoroides. 


\section{Komposisi Jenis Lamun}

Lamun pada setiap stasiun tumbuh baik dan saling berasosiasi, sehingga membentuk suatu padang lamun. Hal ini diduga karena stasiun tersebut berdekatan dengan ekosistem terumbu karang, sehingga padang lamun dapat terlindung dari hempasan ombak yang kuat, dan juga adanya suplai nutrien dari ekosistem terumbu karang di depannya.

Jenis lamun yang ditemukan di lokasi penelitian dapat dilihat pada gambar 2 .

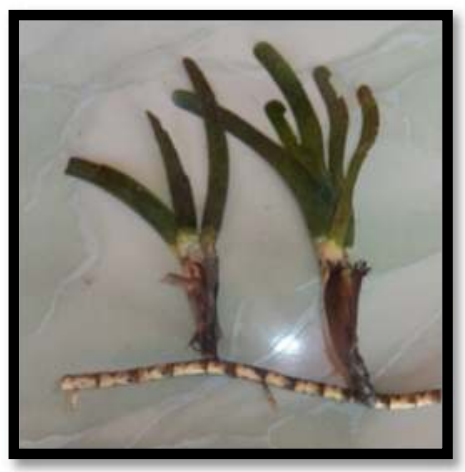

Thalassia hemprichii

Gambar 2. Jenis-jenis lamun yang ditemukan di lokasi penelitian

Persentase komposisi jenis lamun yang ditemukan di lokasi penelitian dapat dilihat pada Gambar 2, jenis lamun adalah Enhalus Acoroides dan Thalassia hemprichii. Kedua spesies tersebut adalah memiliki pola distribusi yang terpusat di daerah tropis dan salah satu berada pada Perairan Pulau Lantang Peo.

\section{Kerapatan Jenis Lamun}

Berdasarkan kerapatan jenis, ada dua jenis lamun yang memiliki nilai menonjol dibandingkan dengan yang lain yaitu Enhalus acoroides dan
Thalassia hemprichii. Hal ini memperlihatkan bahwa jenis lamun tersebut mampu beradaptasi pada substrat lumpur berpasir. Tomascik etal..(1997) menyatakan bahwa Enhalus acoroides hidup pada daerah dangkal yang tertutup lumpur pasir dan mempunyai toleransi yang tinggi pada daerah terbuka atau tidak terendam air. Hasil analisa kerapatan jenis lamun yang diperoleh selama penelitian seperti yang disajikan pada gambar 3. 


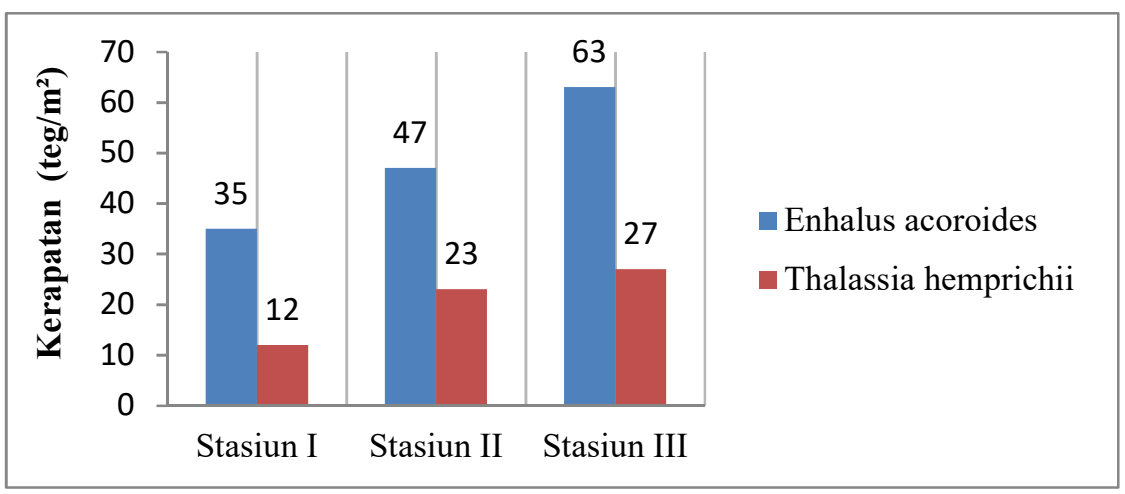

Gambar 3. Kerapatan jenis lamun diperairan PulauLantang Peo

Berdasarkan Gambar 3 di atas dapat dilihat bahwa setiap jenis lamun memiliki kerapatan jenis yang berbedabeda. Kerapatan jenis lamun per satuan luas sangat bervariasi tergantung kepada jenis lamun. Hal ini disebabkan oleh masing-masing spesies lamun memiliki tipe morfologi daun yang berbeda. Selain itu. Tipe substrat berperan dalam mengelolah nutrien dan kestabilan lamun di perairan. Sebagaimana menurut Kiswara (1997) bahwa kerapatan lamun juga dipengaruhi oleh kedalaman, kecerahan, dan tipe substrat.Pengamatan padang lamunmenggunakan metode visual, tidak hanya yang terdapat di transek saja yang diamati tetapi di sekitar lokasi penelitian.
Pengidentifikasi padang dengan cara melihat foto-foto yang diambil pada saat pengamatan.

\section{Penutupan Jenis Lamun}

penutupan atau penaungan ruang oleh lamun. Informasi mengenai penutupan sangat penting untuk mengetahui kondisi ekosistem secara keseluruhan serta sejauh mana lamun mampu memanfaatkan luasan yang ada. Nilai kerapatan saja belum tentu dapat menggambarkan tingkat penutupan suatu spesies karena nilai penutupan selain dipengaruhi oleh kerapatan juga sangat erat kaitannya dengan tipe morfologi spesiesnya. Persentase penutupan lamun yang ditemukan di lokasi penelitian dapat dilihat pada gambar 4 . 


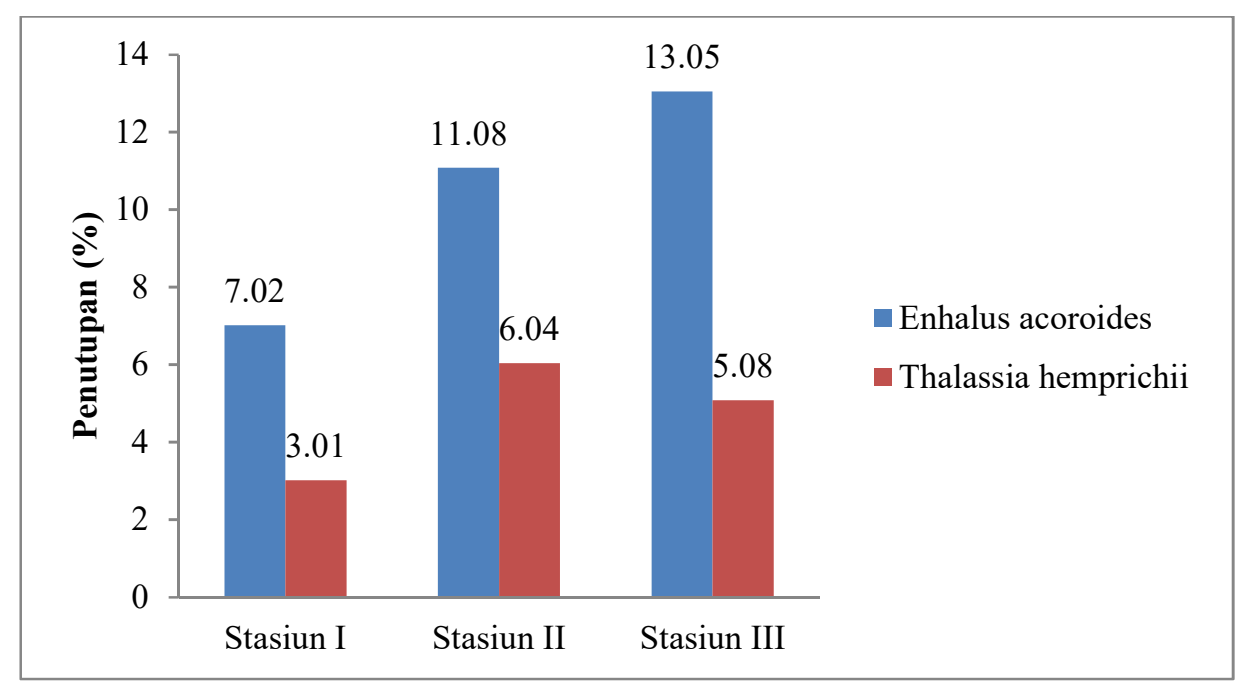

Gambar 4. Penutupan jenis lamun diperairan Pulau Lantang Peo

Secara keseluruhan, penutupan ratarata jenis lamun di perairan PulauLantang Peo didominasi oleh Enhalus acoroides (31,15\%), kemudian Thalassia hemprichii (14,13\%). Persen penutupan yang diperoleh ini lebih tinggi dibandingkan dengan hasil yang diperoleh Kamri (2004), yang menemukan Enhalus acoroides dengan persentase penutupan sekitar 70\%, Cymodocea serullata sekitar 21,45\%, Halodule uninervis sekitar 1,45\%, dan Syringodium isoetifolium sekitar 0,06\%. Hal ini disebabkan oleh perbedaan lokasi pengukuran.

\section{Pertumbuhan Panjang Ikan Baronang}

Hasil penelitian pertumbuhan panjang ikan baronang mendapatkan ukuran S. canaliculatus dengan panjang pada stasiun penelitian dengan ukuran rata-rata panjang awal $10 \mathrm{~cm}$ dan ukuran panjang akhir $11 \mathrm{~cm}$ di stasiun I dengan jarak pertumbuhan $1 \mathrm{~cm}$ selama penelitian yaitu kurun waktu 2 bulan, selengkapnya dapat dilihat pada Gambar 5. Pada stasiun II didapat panjang awal $10 \mathrm{~cm}$ dan panjang akhir $12 \mathrm{~cm}$ sedangkan untuk stasiun III dengan jarak pertumbuhan $2 \mathrm{~cm}$ dengan petumbuhan awal $10 \mathrm{~cm}$ dan pertumbuhan akhir 13 cm. Menurut Allen (1999) Siganus canaliculatus mencapai ukuran dewasa adalah $20 \mathrm{~cm}$, sementara menurut Kuitern (2009) Siganus canaliculatus dapat mencapai ukuran panjang sampai $30 \mathrm{~cm}$. 


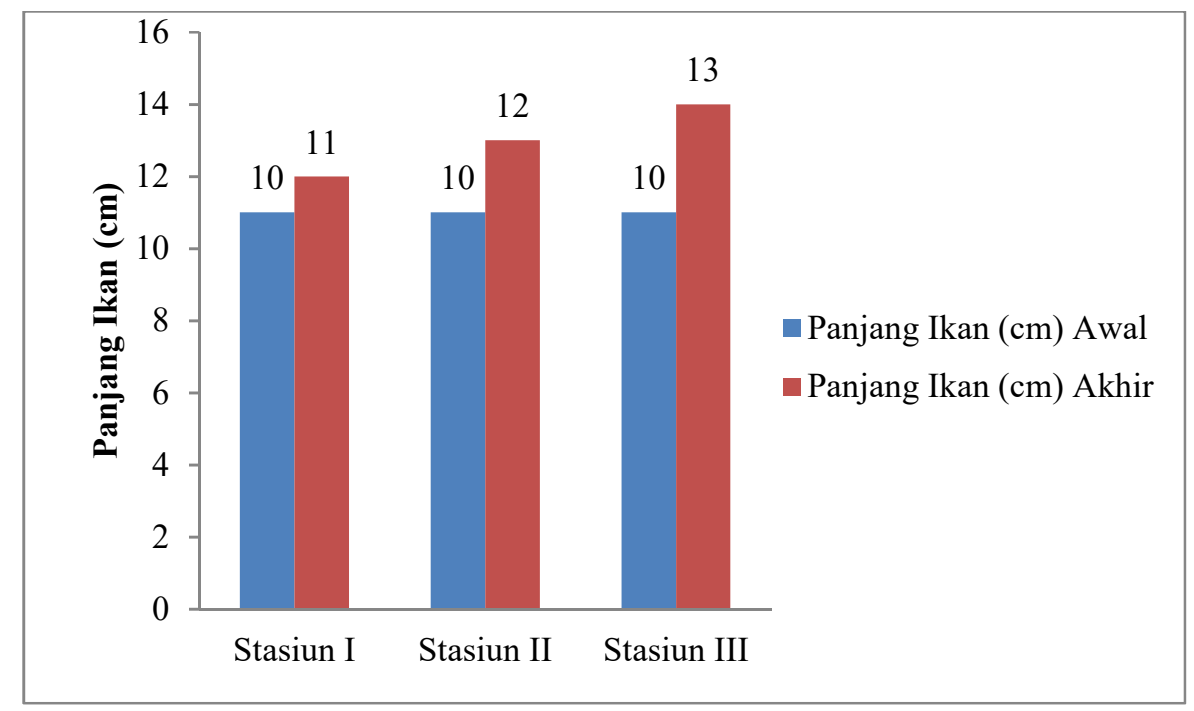

Gambar 5. Pertumbuhan Panjang Ikan Baronang

5. Pertumbuhan Berat Ikan waktu pengamatan didapatkan hasil

Baronang

Pertumbuhan Berat ikan baronang Gambar 6. yang berbeda-beda ditampilkanpada

dalam setiap stasiun pengamatan dan

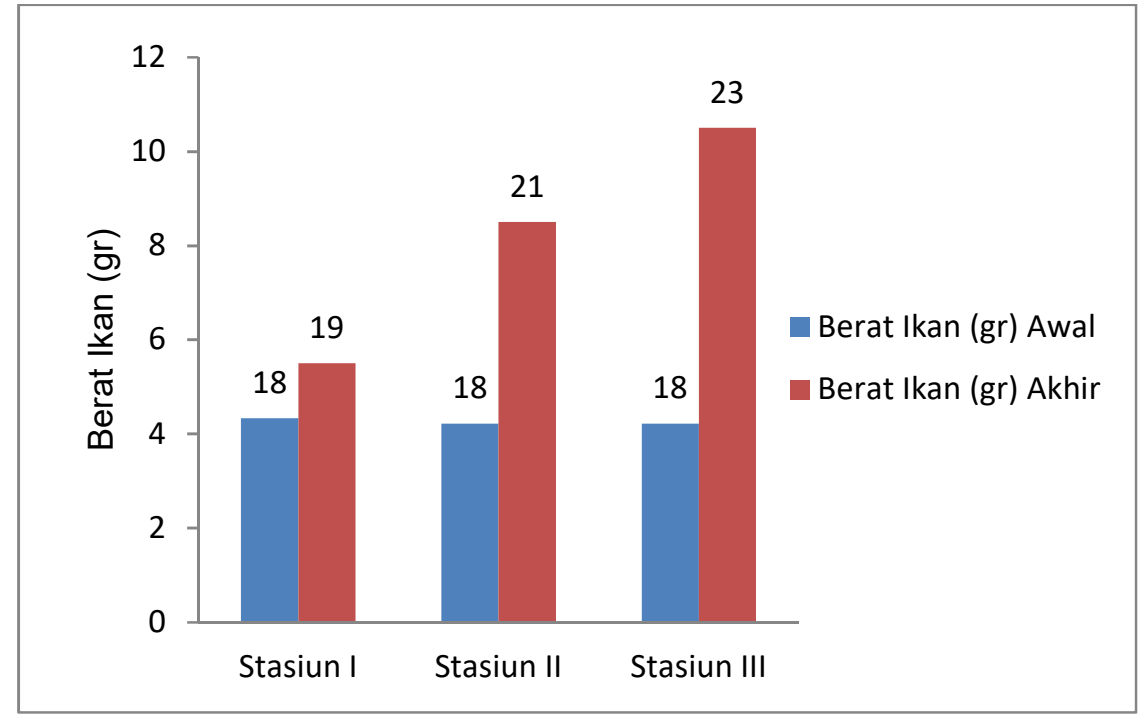

Gambar 6. Pertumbuhan Berat Ikan Baronang

Secara keseluruhan berdasarkan dalam lambung S.canaliculatus adalah uraian di atas, dapat disimpulkan potongan lamun dengan total bahwa pertumbuhan berat ikan dalam komposisi diatas $90 \%$. Menurut Kordi setiap stasiun dengan struktur (2009), ikan baronang tergolong kerapatan lamun yang berbeda herbivora dengan makanan utamanya mempunyai kecepatan pertumbuhan berupa lamun, alga atau lumut, ikan yang berbeda. Terlihat bahwa secara pada tingkat larva memakan plankton umum jenis makanan yang ditemukan 
dan menjadi herbivora saat mulai aktif mencari makan.

\section{Aspek Pengelolaan.}

Pengelolaan perikanan dalam rangka mempertahankan hasil maksimum dari sumberdaya dapat dilakukan melalui berbagi pendekatan, termasuk pendekatan secara biologi. Pendekatan secara biologi ini dilakukan dengan mengkonservasi stok ikan dan menhindari kondisi tangkap lebih. Diharapkan ikan yang ditangkap jumlahnya seimbang dengan rekruitmen alamiahnya.

Agar populasi sumberdaya ikan baronang di Pulau Lantang Peo tetap berlanjut, diperlukan usaha-usaha sejak dini untuk mempertahankan kelestarian sumberdaya ini.

\section{Perlindungan Terhadap} Habitat

Tingginya aktivitas masyarakat di sekitar padang lamun Perairan Pulau Lantang Peo seperti pembangunan transportasi laut, penggalian pasir, dan pelabuhan, baik secara langsung maupun tidak langsung dapat mempengaruhi eksistensi lamun dan lambat laun akan mengganggu peran ekologis padang lamun sebagai daerah perlindungan maupun mencari makan bagi ikan baronang dan biota laut lainnya. Untuk mengantisipasi hal ini, perlu dilakukan pengawasan maupun pembatasan (zonasi) terhadap aktivitasaktivitas tersebut sehingga upaya pemanfaatan dan perlindungan habitat dapat berlangsung secara seimbang.

\section{Penggunaan Alat Tangkap}

Penggunaan alat tangkap yang lazim dipakai oleh nelayan setempat dengan alat tangkap berukuran kecil atau ramah lingkungan yang tidak menggunakan bom atau bius dan hasil tangkapan yang di peroleh sebagian besar adalah anakan ikan baronang. Oleh karena itu, dalam rangka menyediakan kesempatan hidup bagi anakan ikan baronang, alat tangkap perlu diperhatikan, sehingga ukuran minimal hasil tangkapan lebih besar. Penggunaan jaring insang atau jaring pantai dengan ukuran mata jaring yang lebih besar memungkinkan ikan hasil tangkapan yang diperoleh adalah ikanikan dewasa sedangkan juvenil atau ikan ukuran anakan bisa tetap tumbuh dan berkembang. Hal praktis yang dapat dilakukan adalah melibatkan nelayan untuk berpatisipasi menjaga kelestarian stok ikan dengan cara memberikan pengertian mengenai dampak negatif dari penggunaan alat tangkap dengan ukuran mata jaring yang berukuran kecil. 


\section{Melakukan}

\section{Budidaya}

Usaha penangkapan ikan baronang di padang lamun PulauLantang Peo tidak hanya untuk memenuhi kebetuhan komsumsi namun juga untuk dimanfaatkan sebagai ikan umpan. Kondisi ini akan memberikan tekanan terhadap ikan-ikan berukan kecil. Salah satu alternatif dalam rangka melindungi ikan-ikan tersebut adalah menyediakan ikan umpan termasuk didalamnya ikan komsumsi melalui kegiatan budidaya. Kegiatan budidaya ini juga diharapkan dapat mengurangi tekanan penangkapan ikan di padang lamun, sehingga ketersediaan sumberdaya ikan-ikan muda termasuk ikan barong di padang lamun Pulau sembilan dapat berkelanjutan (Badan Pusat Statistik Takalar, 2015).

\section{KESIMPULAN}

1. Karakteristik komunitas lamun di perairan Pulau Lantang Peo merupakan Padang Lamun yang terdiri dari Enhalus acoroides dan Thalassia hemprichii yang memiliki nilai kerapatan secara keseluruhan kategori jarang dengan persen penutupan relatif rendah di lokasi penelitan hal ini disebabkan tinggi aktivitas masyarakat pada Pulau Lantang Peo.
2. Pertumbuhan ikan baronang yang tinggi cenderung dijumpai pada stasiun II dan stasiun III. Hal ini menunjukan bahwa di staiun II dan stasiun III terlihat kerapatan padang lamun yang bagus, bila dibandingkan dengan stasiun I yang tingkat kepadatannya sangat jarang.

3. Strategi pengelolaan dalam pengembangan pemanfaatan ikan baronang secara berkelanjutan meliputi; perlu upaya perlindungan terhadap habitat ekosistem padang lamun, penggunaan alat tangkap yang ramah lingkungan dan kegiatan budidaya.

\section{SARAN}

1. Perlu dilakukan penelitian pembanding dengan waktu pengamatan yang relatif lama agar mendapatkan hasil yang maksimal dalam pemanfaatan ekosistem padang lamun untuk kegiatan budidaya ikan baronang yang ramah lingkungan tanpa merusak ekosistem lainnya

2. Perlu dilakukan penelitian lanjutan untuk mendapatkan gambaran distribusi dan stok biomassa ikan baronang sehingga ketersediaan sumberdaya ikan baronang di padang lamun tetap lestari. 


\section{UCAPAN TERIMA KASIH}

Hasil kajian ini merupakan bagian dari penelitian Tesis dan penulis mengucapkan terima kasih kepada para dosen pembimbing dan dosen penguji. Peneliti juga mengucapkan banyak terimah kasih kepada Ketua Prodi Manajemen Pesisir dan Teknologi Kelautan serta Direktur Pasca Sarjana yang telah memberi kesempatan untuk melanjutkan pendidikan di PPS UMI.

\section{DAFTAR PUSTAKA}

Allen, G. 1999. Marine Fishes of South-East Asia; A guide for anglers and divers. Periplus Editions. Singapore. 292 pp.

Arifin dan Jamaluddin. 2005. Studi kondisi dan potensi ekosistem padang lamun sebagai daerah asuhan biota laut. Jurnal ilmuilmu perairan dan perikanan Indonesia. Fakultas ilmu kelautan dan perikanan. Universitas Hasanuddin. Makassar.

Basyari, A. Danakusumah, Philip, T. I. Pramu, S. Mustahal, Isyra, M. 1987. Budidaya Ikan Baronang (Siganus canaliculatus). Sub Balai Penelitian Budidaya Pantai Bojonegoro. Semarang Brower, JE. Zar, JH. Ende, von, CN. 1990. Field and laboratory methods for general ecology. Dubuque: WCB Publishers.

Badan Pusat Statistik, 2015. Takalar Dalam Angka. Kabupaten Takalar, Sulawesi Selatan.

BPP-PSPL. 2009. Studi Potensi Pengembangan Budidaya Laut di Lokasi Coremap II Kabupaten Lingga. Laporan akhir. Kerjasama Pusat
Penelitian Oceanografi

(Program Rehabilitasi dan Pengelolaan Terumbu Karang/COREMAP II) LIPI dengan Badan Penelitian dan Pengembangan Pengelolaan Sumberdaya Perairan dan Lingkungan (BPP-PSPL) Universitas Riau, Riau.

English, S. Wilkinson, C. Baker, V. 1994. Survey mannual for tropical marine resource. Townville, Australia: ASEANAustralia Marine Science Project: Living Coastal Resources by Australian Institute of Marine science.

Faika, S. 2010. Analisis Kandungan Logam Timbal pada Ikan Beronang (Siganus canaliculatus) Asal Pulau Tanakeke Kabupaten Takalar.Jurnal. Jurusan Kimia Fakultas MIPA. Universitas Negreri Makassar.

Gilanders, B. M. 2006. Seagrasses, Fish, and Fisheries. In: Larkum, A.W.D., Orth, R.J., Duarte, C.M. (Eds.), Seagrasses: Biology, Ecology, and Conservation.

Kiswara, W. 1997. Struktur komunitas padang lamun perairan Indonesia. Inventarisasi dan evaluasi potensi laut pesisir II. Jakarta: Pusat Penelitian dan Pengembangan-LIPI.

Kordi, M. G. H. 2009. Budidaya Perairan.Buku II. Citra Aditya Bakti. Bandung. 964 pp.

Kuitern RH and Debelius H. 2006. Word atlas of marine fishes. Franffurt: IKANUnterwasserachic. 358p.

Lam, TJ. 1974. Siganids: their biology and mariculture potential. Aquaculture.

Lamerburu, E. 2009. Analisa kualitas air dan produktivitas primer ekosistem lamun bagi kehidupan ikan baronang 
(Siganus canaliculatus) di perairan teluk saumlaki kabupaten maluku tenggara barat. Tesis. Program Magister Bidang Keahlian Teknik Dan Manajemen Pantai Jurusan Teknologi Kelautan Fakultas Teknologi Kelautan Institut Teknologi Sepuluh Nopember Surabaya.

Mutmainnah. 2005. Pengembangan Pemanfaatan Sumberdaya Kepulauan Pulau Tanakeke Kabupaten Takalar Provinsi Sulawesi Selatan.Jurnal bisnis perikanan. Fakultas Perikanan dan Ilmu Kelautan. Universitas Khairun. Ternate.

Zulfikar, M. Birawida, A. B. Ruslan. 2013. Kandungan Timbal $(\mathrm{Pb})$ Pada Air Laut Dan Ikan Baronang

(Siganus canaliculatusinus) Di Perairan Pesisir Kota Makassar. Jurnal. Bagian Kesehatan Lingkungan Fakultas Kesehatan Masyarakat Universitas Hasanuddin, Makassar.

Rappe, R. A. Budimawan, Fahyra, H. A. 2011. Preferensi makanan dan daya ramban ikan baronang, Siganus canaliculatus pada berbagai jenis lamun.Jurnal. Jurusan Ilmu Kelautan, Fak.Ilmu Kelautan dan Perikanan Universitas Hasanuddin, Makassar.

Tomascik, T. Mah, AJ. Nontji A and Moosa MK. 1997. The Ecology of The Indonesia Seas. Printed In The Republic of Singapore. P 829-900. 